\title{
LA LUCHA POR LA TIERRA EN LA HUASTECA POTOSINA (MÉXICO): DE PEONES A PATRONES ${ }^{1}$
}

\author{
Virginia Jabardo Pereda \\ Instituto de Geografía. Universidad Nacional Autónoma de México \\ virginiajabardo@yahoo.es
}

\section{RESUMEN}

El presente trabajo consiste en un análisis acerca de las luchas por la tierra que se han venido produciendo en la región mexicana de la Huasteca Potosina, principalmente a raíz de la puesta en marcha del proyecto Pujal-Coy en 1973, cuando ocurre una transformación espacial que provoca toda una serie de conflictos por la apropiación del territorio a manos de nuevos pobladores frente a las instancias de gobierno encargadas del reparto agrario. Este proceso aparecerá marcado por la transformación del estatus socioeconómico de un importante colectivo en el momento en el que se convierten en propietarios de tierras.

La metodología desarrollada es de carácter interdisciplinar al combinar el análisis geopolítico a escala local, el trabajo etnográfico en comunidades rurales y la revisión histórica. El resultado de la investigación ha sido la comprensión de la lógica espacial que define a esta región de México a partir de las contradicciones entre las prácticas espaciales hegemónicas y los contra-espacios que las poblaciones locales construyen como alternativa a las primeras.

Palabras clave: México; Huasteca Potosina; Pujal-Coy; movimiento por la tierra; luchas agrarias; territorio.

\section{ABSTRACT}

\section{The struggle for land in Huasteca Potosina (Mexico): From labourers to owners}

This paper analyses the struggle for land in Huasteca Potosina, a Mexican region, mainly due to the Pujal-Coy Project in 1973, when a spatial transformation occurred that provoked several conflicts against governmental agencies responsible for agrarian distribution, owing to the territorial appropriation by new settlers. This process would be marked by the transformation of the socioeconomic status of a large social group when they became land owners.

The methodology used is interdisciplinary and combines geopolitical analysis on a local scale, ethnographic work in rural communities and a historical review. The result has been the understanding of a spatial logic that defines this Mexican region on the basis of the contradictions between hegemonic spatial practices and the counter-spaces that local people create as an alternative.

Keywords: Mexico; Huasteca Potosina; Pujal-Coy; agrarian movement; agrarian struggles; territory.

\section{A MODO DE INTRODUCCIÓN}

El interés de la presente investigación radica en la necesidad de llevar a cabo un análisis acerca de la situación que actualmente define al mundo rural de la Huasteca Potosina (México). Durante la década de los noventa del pasado siglo surgieron múltiples trabajos que abordaron la realidad por la que atravesaba la región. Sin embargo, estos se agotaron. El hecho de que a día de hoy se esté relanzando la tercera fase del proyecto de riego Pujal-Coy, iniciado en el año 1973 justifica este trabajo. El mismo inauguró un proceso

1 El presente trabajo es resultado de la investigación llevada a cabo en el marco de la beca posdoctoral de la Universidad Nacional Autónoma de México 2014/2015. 
de capitalización de la tierra en la Huasteca, beneficiando al sector campesino y ganadero por la dotación de tierras impulsada a través de las instituciones gubernamentales. Estos actores que tradicionalmente habían desempeñado labores como peones en ranchos y haciendas, pasarían a convertirse en propietarios rurales. De esta manera se crearon nuevas entidades territoriales, los denominados como Nuevos Centros de Población Ejidal (NCPE), donde se asentaron familias llegadas de diversos puntos del país.

El espacio percibido y apropiado por los actores sociales se encuentra en el centro de las reflexiones del trabajo de Hoffman y Salmerón (1997) quienes establecen las vertientes que determinan la puesta en valor del territorio entendido como espacio susceptible del uso, control y explotación por los sujetos sociales y las instituciones de poder. Las poblaciones locales definen sus estrategias en términos culturales y tecnológicos con las que adaptarse a las condiciones impuestas por factores exógenos, fundamentalmente por la implementación de políticas de ordenación del espacio, al tiempo que contribuyen a la transformación del mismo y a la creación de nuevas territorialidades.

Las poblaciones locales de la Huasteca han activado estrategias adaptativas para lograr un manejo y gestión del territorio acorde con las necesidades productoras y reproductoras de los NCPE, construyendo así su propia espacialidad, confrontada con las prácticas espaciales hegemónicas impuestas desde instancias gubernamentales. Dos lógicas pugnan entonces por imponerse. La primera de ellas actúa a través de los poderes estatales y es ejercida por grupos técnicos de expertos que construyen una "representación del espacio" dominante en términos lefebvrianos (Lefebvre, 1991). Pretende marcar una tendencia conducente a la privatización de las propiedades ejidales, mientras que éstas se constituyen sobre estructuras colectivas y despliegan sus estrategias de acción en las formas de la vida cotidiana, donde se construyen las "prácticas espaciales".

Resulta interesante para comprender las dinámicas socioespaciales que tienen lugar en la Huasteca Potosina, discernir acerca de los modelos de manejo territorial. Ante tal escenario cabe plantearse: ¿cuáles son las estrategias de acción de los actores sociales en cuanto al uso del espacio?, ¿qué tipo de impactos a nivel socioeconómico han tenido lugar en la región provocados por la reestructuración agraria de la época contemporánea? y por último ¿cuál es la espacialidad resultante de la intersección de las diferentes territorialidades desempeñadas desde el ámbito institucional y desde la cotidianeidad de los pobladores locales? Sobre este conjunto de cuestiones pivotará el presente trabajo. Se partirá para ello de la hipótesis de que las luchas agrarias en la Huasteca Potosina no han sido capaces de revertir el problema de la desigualdad en el acceso a la tierra, sino que por el contrario, los pequeños productores han sido absorbidos por la tendencia capitalizadora del agro.

Los objetivos principales que se pretenden alcanzar son entender el modo en el que aquellos sujetos que históricamente han ocupado los escalones más bajos de la pirámide social del campo mexicano han acabado conquistando, en esta región, un lugar que les ha sido negado durante siglos y del que se habían mantenido excluidos, convirtiéndose en propietarios de tierras y en dueños del proceso de producción agraria. En segundo término se trata de explorar los elementos conflictivos que determinan la tenencia de la tierra y el acceso a ésta en la zona más septentrional de la Huasteca Potosina, a fin de visibilizar los mecanismos espaciales diseñados tanto por instituciones de gobierno encargadas en determinar el esquema de dicha tenencia, como por los NCPE.

En cuanto a la metodología desarrollada cabe señalar que el estudio se llevó a cabo en dos municipios concretos: Tamuín y Ébano, en donde se acudió a instancias gubernamentales -fundamentalmente Comisión Nacional del Agua (CONAGUA) y Secretaría de Agricultura, Ganadería, Desarrollo Rural y Pesca (SAGARPA)-, sedes de organizaciones rurales y asociaciones ganaderas. Asimismo se visitaron comunidades con población mayoritariamente indígena junto con los NCPE de Ponciano Arriaga y Pujal, en los que se llevaron a cabo entrevistas con informantes clave previamente contactados. Cabe aclarar un aspecto que surgió durante el trabajo de campo y el cual determinó en buena medida la investigación: habiéndose previsto acudir a otros poblados (Nuevo Aquismón, Santa Martha o Aurelio Manrique) fue descartado debido a las recomendaciones que instaban a evitar penetrar más hacia el interior por la presencia de grupos de delincuencia organizada. Se modificaron ligeramente, en consecuencia, los criterios de elección de las poblaciones objeto de estudio, concediéndose absoluta prioridad a la seguridad y a las facilidades de acceso a los centros de población.

Asimismo ha resultado esencial la consulta de fuentes bibliográficas de trabajos ya elaborados además de documentos de archivos de distintas instituciones.

Todo ello ha permitido plantear el estado de la cuestión de los procesos agrarios de las luchas por la tierra como marco analíticos. Gran parte de los trabajos que tienen por objeto de análisis la estructura 
agraria de México, coinciden en subrayar las transformaciones sometidas al campo a lo largo del siglo XX, fruto de las dos reformas agrarias de dicho periodo (1917 y 1992). Las escuelas de pensamiento que atienden la cuestión agraria no sólo en México, sino en el conjunto de países de América Latina visibilizan una serie de fenómenos: los conflictos sociales ocurridos en el campo y de qué manera han afectado estos al sector campesino, cuestiones tratadas por las corrientes más críticas. Por el contrario, aquellos trabajos más condescendientes con la acción de los gobiernos de turno se muestran más interesados en buscar soluciones que enfrenten el problema de la modernización del agro en el país y el desarrollo rural.

La situación de desigualdad social que ha definido la sociedad rural en América Latina, ha centrado las miradas de los análisis estructuralistas. Si bien esto ha ocurrido desde la década de los setenta del siglo XX cuando se dejó sentir una fuerte impronta marxista encargada de visibilizar la proletarización agraria consecuencia de las relaciones capitalistas que han afectado al campo.

No obstante, al comienzo del pasado siglo los estudios dedicados al mundo rural adoptaron un enfoque local, poniendo su interés en los particularismos geográficos y etnográficos. Estos fueron reemplazados por otro tipo de trabajos que partían de una perspectiva funcionalista.

A día de hoy el estudio de las relaciones de poder copan mayoritariamente las páginas de las investigaciones acerca de la cuestión agraria, en México y en América Latina, discutiendo acerca del papel del Estado y su relación con las organizaciones rurales, la irrupción del modelo neoliberal en el campo, los conflictos consecuentes por la lucha por la tierra y los embistes de las políticas de mercado. Ponen entonces de manifiesto el estrecho vínculo entre los procesos territoriales y los procesos identitarios (Bartra y Otero, 2008), lo que ayuda a entender el porqué de la tendencia al análisis en los movimientos indígenas y en dimensionar la cuestión étnica del mundo rural.

En síntesis, las corrientes que marcan el estudio del mundo agrario en México se dividen entre aquellas que perciben un escenario catastrófico que atiende a la agudización de la crisis y los conflictos; una perspectiva moderadamente pesimista que apuesta por aplicar medidas prudentes para mejorar la situación de los pequeños productores en el mediano plazo y un escenario optimista que vislumbra la posibilidad de combatir la pobreza rural a través de la implementación de una políticas públicas conducentes a fomentar la productividad (Warman, 2001).

\section{CONTEXTO GEOGRÁFICO}

La Huasteca Potosina está representada en espacios territoriales correspondientes a varios estados: Tamaulipas, Veracruz, Hidalgo, Puebla y San Luis Potosí. Atendiendo a una clasificación geomorfológica, dicha región quedaría dividida en la Huasteca Alta en la Sierra Madre Oriental, y la Huasteca Baja en la llanura costera del Golfo de México.

El marco espacial de la investigación se circunscribe al área delimitada por los municipios de Ébano y Tamuín (Estado de San Luis Potosí), la parte más septentrional de la Huasteca Potosina (Figura 1). El clima predominante es de tipo cálido subhúmedo $\mathrm{Aw} 0$, con una temperatura promedio de 22 grados, que, sin embargo, no evita los efectos de la canícula, los ciclones y los nortes (Baca del Moral, 1996).

Figura 1. Localización área de estudio

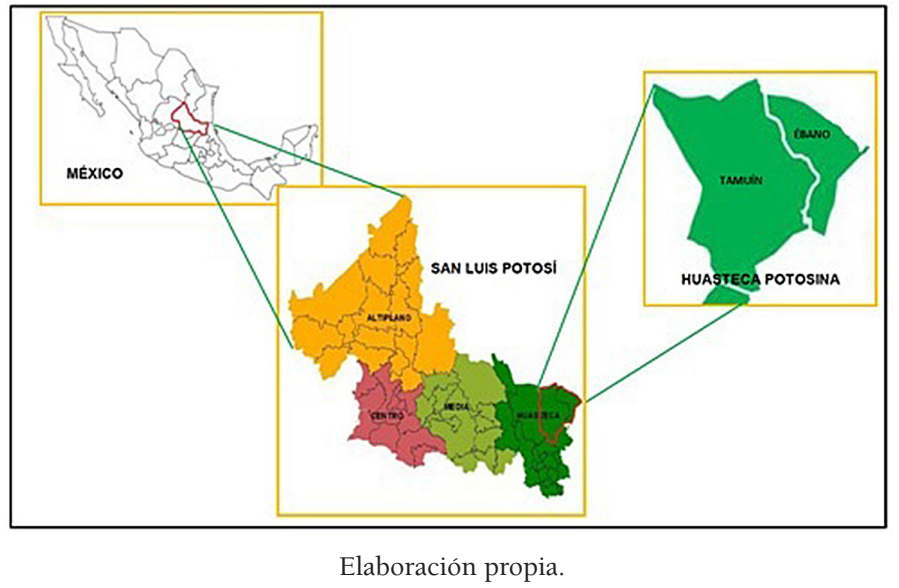


Cronológicamente, este trabajo se acota a un lapso de tiempo restringido que transcurre desde el último cuarto del siglo XX hasta la actualidad. Sin embargo y para entender la realidad del momento presente, se hará un repaso de algunos de los acontecimientos fundamentales que contribuyen a explicar la historia del agro en esta región.

\section{REVISIÓN HISTÓRICA DE LA ESTRUCTURA DE LA TIERRA EN LA HUASTECA POTOSINA}

\subsection{Periodo colonial}

La Huasteca fue invadida por tropas españolas comandadas por Hernán Cortés, quien debió enfrentar la resistencia de las poblaciones locales. A partir de ese momento comenzó el despoblamiento de esta región propiciado por el comercio de esclavos implantado por los conquistadores, que destinaba el capital humano a las Antillas.

Dado que existe abundante literatura sobre la historia de la conquista europea en el espacio amerindio, se evitará caer en repeticiones descriptivas. Pero hay un matiz que convienen aclarar. Es la situación, de algún modo, privilegiada que vivieron las poblaciones locales referida a la propiedad agraria si se compara con otros periodos de la historia post-colonial. Las repúblicas de indios posibilitaron la continuidad de un tipo de manejo y gestión del territorio y de los recursos al interior de dichas jurisdicciones. No podemos pasar por alto las acciones de los franciscanos en la Huasteca Potosina, quienes de la mano de Fray Junípero Serra fundaron múltiples centros misionales, articulados en una red de núcleos de población étnica congregada para facilitar su sometimiento al poder real ejercido a través de la institución eclesiástica. Por medio de las mercedes reales, otorgadas por los virreyes, la corona concedió tierras tanto a locales como conquistadores en recompensa a la empresa de la conquista, constituyendo estas el germen de lo que serían las futuras haciendas en esta región ${ }^{2}$.

\subsection{Periodo liberal}

Las comunidades indígenas huastecas disfrutaban de un acceso colectivo a la tierra y los recursos, aun careciendo en muchos casos de títulos de propiedad que les amparase legalmente ante posibles expropiaciones. La destrucción de la propiedad comunal sumado a las dinámicas socioeconómicas impuestas por el nuevo régimen liberal les obligaron a incorporarse a las haciendas como mano de obra ${ }^{3}$.

De modo similar a como ocurrió en el resto de repúblicas decimonónicas latinoamericanas, en México se creó una reforma agraria cuyo fin era la desamortización de los bienes comunales y eclesiásticos. Se previó que la promoción de la propiedad privada y el incremento de la productividad de la tierra se convirtieran en los motores de la nueva nación moderna al estimular la entrada de capitales en forma de impuestos al Estado. La Ley Lerdo del año 1856 institucionalizó entonces el proceso de desamortización y privatización agraria. El vínculo que ligaba a propietarios privados-ciudadanos impidió a las sociedades indígenas ejercer sus derechos como sujetos nacionales, al perder la titularidad de sus propiedades de tierras.

Asimismo se propició que los grandes hacendados acaparasen cada vez más y mejores tierras, fortaleciendo su poderío económico ${ }^{4}$. En la Huasteca Potosina las planicies constituyeron, por lo tanto, los espacios predilectos para estos y el sector ganadero se fue consolidando en la región como el principal a nivel económico-productivo. Los campesinos se vieron obligados a cultivar sus milpas en la sierra, en el terreno más abrupto debido a la morfología del suelo.

En relación a lo ocurrido en otras regiones del país, la legislación que debía hacer efectivo el proceso de expropiación de tierras, se implementó con posterioridad en la Huasteca. La condición periférica que ha marcado el devenir de esta región explica el porqué de tal dilación. Consecuentemente los pueblos

2 La primera merced real que se concede en la Huasteca Potosina la reciben los indios de Tamuín en el año 1542 de manos del virrey don Antonio de Mendoza (Meade de Angulo, 1983).

3 Eric Wolf (1972) ha trabajado en profundidad la ocupación de mano de obra indígena en las haciendas y la polarización del mundo rural en el periodo colonial y republicano y con especial interés la cuestión agraria durante el periodo revolucionario.

4 No se puede ignorar la afinidad de grandes hacendados con la esfera política regional, llegando a ocupar cargos públicos avalados por su posición económica, lo que ha prevalecido hasta la actualidad. 
indígenas lograron conservar, en buena medida, sus antiguas propiedades. Hasta la década de los setenta del siglo XIX no se impuso el nuevo régimen de tierras que, esta vez sí, dejaba a los pueblos indígenas, desde el punto de vista jurídico, desamparados al anteponer los derechos de los propietarios privados a la tenencia comunal.

La formalización del proceso de desamortización de la tierra no se haría efectiva hasta la entrada en vigor de la Ley sobre ocupación y enajenación de terrenos baldíos, promulgada el 20 de julio de 1863 por el presidente de la república, Benito Juárez. Finalmente se procedió a la "conversión de los ejidos y terrenos de común repartimiento, en terrenos de propiedad privada, dictando al efecto cuantas disposiciones crea necesarias para el deslinde, fraccionamiento y enajenación de los referidos terrenos" (Barthas, 1993, p. 34). La capitalización agraria fue aprovechada por los grandes propietarios para incrementar la superficie de sus parcelas y enriquecerse así costa de operaciones de compra-venta de tierras que anteriormente habían estado en manos de pueblos indios, de ayuntamientos o incluso de otros propietarios privados incapaces de demostrar su titularidad (Escobar, 2009).

En la Huasteca Potosina el proceso de privatización de la tierra estuvo marcado por dos etapas: de 1870 a 1889, cuando prevalecieron los denuncios de tierras, y de 1889 a 1909, cuando las compañías deslindadoras (Urista-Eisenmann y Rafael García Martínez) desarrollaron su actividad (Fajardo, 2009). Éstas son pieza clave para entender el proceso de privatización de la tierra por encargarse de escriturar las superficies que carecían de título de propiedad, mensurar, delimitar y dar cuenta de aquellas tierras improductivas o baldías que pasaban, por consiguiente, a manos del gobierno federal, quien las traspasaba, en su mayor parte, a grandes propietarios. Tareas por las que recibían hasta un tercio de la tierra sujeta a deslinde y que les granjeó la oposición de todos aquellos ayuntamientos, pueblos indígenas, haciendas y condueñazgos afectados por los deslindes ${ }^{5}$.

El porfiriato logró entonces lo que las leyes liberales habían estado intentando durante 3 décadas: consolidar el proceso de privatización agraria, abrir el mercado de tierras y desintegrar la propiedad comunal.

En el estado de San Luis Potosí hubo que esperar incluso hasta el año 1890 cuando siendo gobernante Díez Gutiérrez se decretó una ley sobre la conversión de ejidos en propiedad privada (Gutiérrez, 2009).

\subsection{Periodo contemporáneo}

Para este periodo la cuestión agraria se articula en torno a dos grandes reformas que pretenden reestructurar el régimen de propiedad de la tierra. La primera de ellas, responsable de la creación de los ejidos como forma de propiedad colectiva, queda recogida en la Constitución de 1917 que en su artículo 27 estipula el reparto de tierras a los campesinos demandantes a partir de las expropiaciones a grandes propietarios.

El trabajo de López (2008) se explica de qué manera una vez más, las medidas aplicadas al campo se harían esperar en el estado de San Luis, esta vez debido fundamentalmente a la oposición de terratenientes, quienes obstaculizaron el proceso.

Ante las promesas de repartición agraria, los campesinos tuvieron que lidiar con los grandes latifundistas que concentraban la tierra. Las condiciones de asfixia económica en las que aquellos se encontraban sumidos, estimuló a muchos a buscar nuevas tierras donde asentarse. No obstante, la situación empeoró a mediados del siglo XX, al impulsarse las políticas de desarrollo rural dirigidas a la capitalización de propiedades ejidales. BANRURAL jugó un papel determinante. Esta entidad financiera otorgaba créditos a campesinos con la intención de que accedieran a un paquete tecnológico para que pudiesen reactivar su actividad en el proceso de producción agrícola. Los resultados no fueron, sin embargo, los esperados. Muchos campesinos entraron en cartera vencida y otros tantos quedaron endeudados.

Sumado a ello, en el año 1992 mediante la modificación del artículo 27 tiene lugar una segunda reforma agraria. Esta vez se pretende fomentar un proceso de privatización de la tierra a través de la derogación del carácter de inalienabilidad, inembargabilidad e imprescriptibilidad del ejido, incorporándolo además al mercado de tierras.

\footnotetext{
5 Forma de tenencia de la tierra referida a un territorio proindiviso, el cual puede ser tanto propiedad privada o comunal, en donde cada uno de los propietarios cuentan con la posibilidad de traspasar libremente los derechos que se posee sobre la tierra al tiempo que pueden acceder al terreno compartido con el resto a través del pago de una cuota (Escobar, 2009).
} 
Todo ello produjo una enorme confusión en el mundo rural de la Huasteca Potosina, afectada al tiempo por una fuerte devaluación de los precios. Es entonces cuando se comenzaron a tramitar los certificados parcelarios individuales para cada ejidatario, lo que tendrá una enorme repercusión en el ámbito rural, por ser uno de los factores responsables de la desarticulación de la estructura colectiva ejidal. Y es que una vez obtenidos los títulos a nivel individual se desmotivó la celebración de asambleas de ejidatarios y de reuniones mensuales en las que se dirimía colectivamente acerca del correcto funcionamiento del ejido y se programaban las actividades del mismo, desvaneciéndose, de esta manera, el compromiso grupal de sus miembros.

\section{TRANSFORMACIONES EN LA ESTRUCTURACIÓN AGRARIA DE LA HUASTECA POTOSINA}

\subsection{Los proyectos de riego}

El proyecto de riego Pujal-Coy va a transformar la estructura agraria de la Huasteca Potosina por un motivo fundamental y es que hasta ese momento apenas existían en esta región propiedades ejidales, sino que el paisaje aparecía poblado por grandes latifundios dedicados esencialmente a la actividad ganadera. Esto cambiará con la implantación del distrito de riego, responsable de la fundación de más de 150 NCPE que vienen a ocupar una superficie de más de 75.000 hectáreas.

Las familias recién llegadas se convirtieron en ejidatarias y dueñas de predios con superficies que oscilaban en torno a las 10 hectáreas ${ }^{6}$. Superficie que en muchos casos se ha ido incrementando al adquirir nuevos terrenos a medida que aumentaban las rentas de sus propietarios, quienes se dedican casi en exclusividad a labores agropecuarias, en particular al cultivo de productos básicos como el maíz o la soya, además de frijol. La producción de las explotaciones familiares se destina esencialmente al mercado regional pero debido a los bajos rendimientos cada vez se promueve más la asociación de diversos propietarios a fin de constituir pequeñas empresas.

La intención aparente del proyecto sería la de impulsar social y económicamente el desarrollo rural de la Huasteca por medio de la redistribución de la tierra a los grupos de campesinos demandantes de tierra. En este proceso el mayor obstáculo a salvar fue la negativa de grandes propietarios al reparto agrario, quienes se opusieron a los decretos expropiatorios que buscaban minar los privilegios que venían acumulando años atrás.

Es desde la década de los cincuenta del pasado siglo que sabemos de algunas propuestas conducentes a impulsar un desarrollo regional a partir de la explotación de cuencas hidrológicas en esta región (Baca del Moral, 1996). Desde entonces y en parte fruto de la implementación de este tipo de proyectos, ha tenido lugar una reestructuración de la tenencia de la tierra. Destaca por encima de cualquier otra iniciativa el programa de Pujal-Coy (1973) con el que se pretendió crear una superficie de riego de hasta 720.000 hectáreas (la más extensa de todo el continente latinoamericano) (Reyes, Aguilar, Aguirre y Trejo, 2006) (Figura 2). Se dedicarían a incrementar el espacio ocupado durante centurias por praderas ganaderas y que serían transformadas en tierras destinadas a cultivos agrícolas entre los que destacaban las oleaginosas, fundamentalmente el maíz y soya, hortalizas y granos básicos como sorgo o frijol. PujalCoy se localizó en la triple frontera comprendida entre el los estados de San Luis Potosí, Tamaulipas y Veracruz.

Para lograr reconvertir esta vasta superficie era prioritaria la expropiación de aquellas tierras en manos de propietarios privados, quienes fueron indemnizados por ello. Muchas estaban a nombre de antiguos militares que habían servido a la república y que fueron compensados con tierras por los servicios prestados. El proceso expropiatorio ocurrió a pesar de las protestas ante tales afectaciones. Inicialmente buena parte de los particulares se negaron a acatar el decreto del gobierno federal y ejercieron presiones

6 Desde principios del pasado siglo se pusieron en marcha los programas de dotación de tierras, destinadas a aquellos que lo solicitaban amparándose en el artículo 3 de la Ley Agraria de 1915. Tal y como narra Hernández (2012) dichas demandas experimentaron un notable incremento a finales de la década de los cincuenta y principios de la década de los sesenta, cuando el Departamento Agrario se vio superado por grupos de campesinos hastiados de la situación de injusticia social en la que habían permanecido sumidos durante años. La mayor parte de estos trabajaban como peones en otras haciendas de la región o incluso de otras zonas del país. Comenzaron a mostrar su desagrado ante la concentración de tierras que definía el paisaje agrario huasteco, enfrentándose además al sector ganadero que copaba el escenario político local. 
para defender su patrimonio. No obstante, optaron mayoritariamente por la indemnización ${ }^{7}$. Pero no les fue permitido formar parte de grupos solicitantes de tierras que acudieron a la región para obtener las parcelas donde establecerse.

Figura 2. Área del proyecto Pujal-Coy

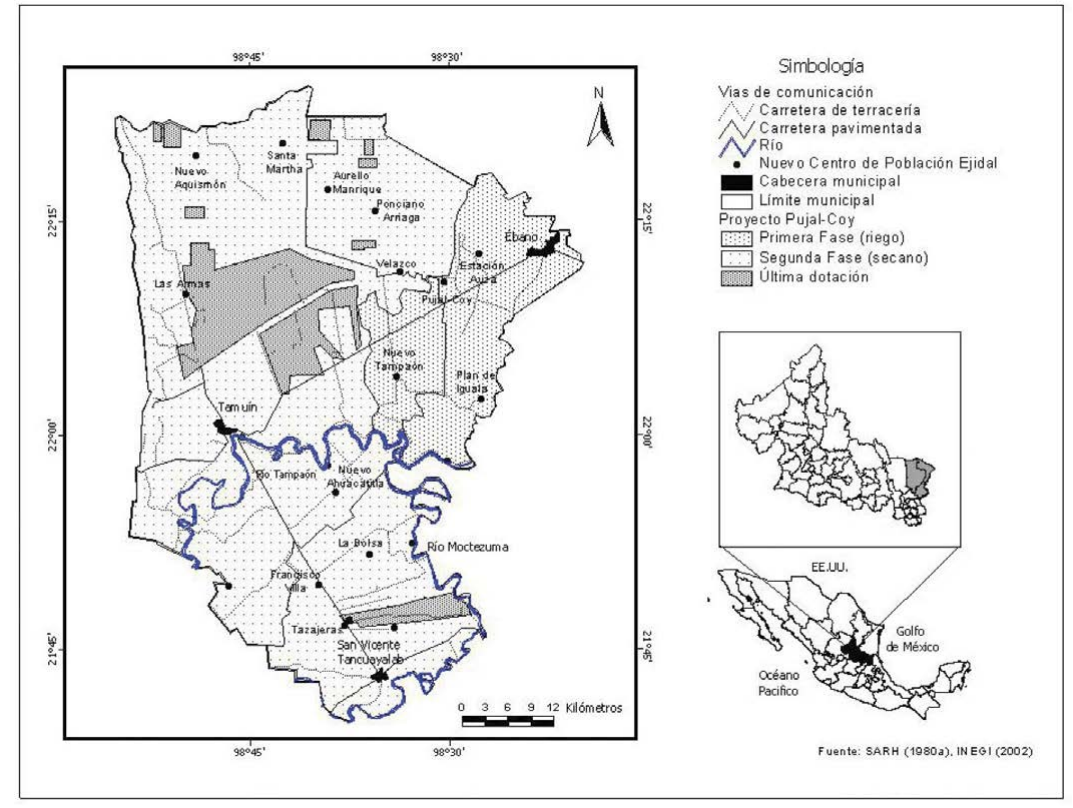

Fuente: Reyes, et al., 2006

La puesta en marcha del proyecto Pujal-Coy propició la intervención directa sobre el medio rural, transformando la propiedad agraria y la tenencia de la tierra en la Huasteca. En dicho contexto se evidenció hasta qué punto las acciones emprendidas por los gobiernos estatales respondiendo a la lógica del capital. Baca del Moral (1993) señala como factores propiciatorios de este proceso de capitalización del agro a la introducción de cultivos destinados al mercado, la promoción de paquetes tecnológicos -tractores, módulos ganaderos, láminas- o la asignación de créditos a campesinos.

Se puede entender entonces la reestructuración de la tenencia de la tierra en la Huasteca Potosina que acarreó el programa de Pujal-Coy, así como la modificación, en buena parte, de los usos del suelo y los cambios en las relaciones productivas entre grandes propietarios y pequeños productores, además de afectar a la estructura orgánica de los movimientos rurales. Habrá que esperar para determinar los resultados de la nueva fase, la tercera, que apenas empieza a ponerse en marcha en su etapa de licitación.

\subsection{El fracaso de las medidas reformistas}

La reestructuración de la propiedad agraria en la Huasteca Potosina se topó con varios factores que imposibilitaron sus objetivos. La desigualdad en el acceso a la tierra constituiría la pieza clave para la eclosión de toda una serie de organizaciones rurales que demandaban mejoras en el campo y ayudas para las familias ejidatarias. No obstante, tales organizaciones debieron asumir las consecuencias de una falta de conocimientos en términos organizativos; una deficiente gestión administrativa; prácticas de corrupción perpetradas junto con empleados públicos de las instituciones estatales sumado a algunos delitos fiscales de los que algunas de ellas fueron acusadas, además de conflictos internos resultado de la confrontación entre facciones opuestas que se disputaban la autoridad y el ejercicio del poder al interior de las organizaciones.

\footnotetext{
7 Una de las estrategias usadas por el sector ganadero para frenar las expropiaciones fueron los documentos de inafectabilidad firmados por el Departamento Agrario, a través de los cuales debían demostrar que durante un periodo superior a los 6 meses previos a solicitud de dicho certificado el propietario del terreno en cuestión lo dedicaba a la explotación ganadera, mecanismo al que los ganaderos de la región recurrieron de manera frecuente a partir de 1940 (Hernández, 2012).
} 
Otro factor que explica el fracaso de la reestructuración agraria en esta región es la implementación de las políticas de ajuste estructural dirigidas a modernizar el campo. Consistieron básicamente en impulsar el gasto y el consumo de los pequeños productores a través de la concesión de créditos que redituarían en inversiones en las propiedades agrarias. Sin embargo, no todos los productores fueron capaces de asumirlo y afectó, en consecuencia, al desarrollo de las actividades de los propios ejidos.

Estos hechos nos permiten, asimismo, entender la injerencia de organismos supranacionales aplicados a través del Programa de Desarrollo Productivo Sostenible para Zonas Rurales Marginadas de la Huasteca Potosina (PDPSZRMHP), dirigido a fomentar el desarrollo sustentable en comunidades con alto riesgo de exclusión (Baca del Moral, 2006). Injerencia porque es con financiación del Banco Mundial que se crea el programa Alianza para el Campo por el que se acuerda pagar parte de la deuda externa contraída pero con la contrapartida de introducir algunas modificaciones dictadas desde fuera en lo que se refiere a políticas agrícolas.

Trabajos como el de Baca del Moral (1996) estiman en 20 millones de pesos la cifra a la que ascendía la cartera vencida para el año 1991 en la zona de Pujal-Coy, lo que condujo a la creación del Fideicomiso para la Cartera vencida (FIRCAVEN) destinado a aquellos productores clasificados como de alta siniestralidad a quienes se es transfería la deuda a PRONASOL, entidad encargada en reestructurar la misma. Al no resultar una alternativa demasiado interesante, fueron surgiendo asociaciones entre empresarios y ejidos con cartera vencida. El primero asumía la deuda del ejido en cuestión y rentaba la propiedad ejidal, a la vez que contrataba a los campesinos de dicho ejido para desempeñar las labores agrícolas a cambio de liquidar la deuda y de obtener e su beneficio y como incentivo un financiamiento (ibíd.).

Interesa especialmente poner de manifiesto algunos efectos muy concretos que Pujal-Coy provocó en el mundo rural de esta región. En primer lugar nos encontramos con una escasa atención prestada al locus de los NCPE, por parte de las instancias encargadas en poner en marcha el proyecto. Fue tal que para el caso del poblado Pujal, los responsables de su diseño no incluyeron un camino de acceso, lo cual llevó a los primeros grupos de pobladores a abrir un sendero a golpe de machete tumbando el monte e incluso a invadir la propiedad de un particular. De esta manera las viviendas fueron construidas por ellos mismos haciendo uso de los recursos que encontraban en el entorno. Hubo que esperar a 1981 cuando tras la petición de materiales efectuada por parte de los comisarios ejidales al gobierno del estado, la Secretaría de Agricultura y Recursos Hidráulicos (SARH) otorgó bloques de construcción.

Desde un principio se careció, por lo tanto, de infraestructuras que posibilitaran unas condiciones de vida dignas a las familias recién instaladas. En segundo lugar el total desconocimiento manejado por los nuevos habitantes en cuanto a labores del campo se refiere. No deja de sorprender la ausencia de cultura agraria de muchos de los miembros que conformaron los grupos de solicitantes de tierras, a quienes costó muchos esfuerzo adaptarse al medio rural. Una parte significativa de ellos provenía de oficios profesionales que nada o muy poco tenían que ver con el campo: carpinteros, zapateros, vendedores, etcétera, y se embarcaron en la aventura de convertirse en campesinos, sin evaluar los riesgos. La consecuencia fue que buena parte de ellos abandonaron la idea de continuar, al carecer de capacidad suficiente o de la experiencia requerida. Es decir, las dificultades a las que se enfrentaron quienes llegaron en un primer momento, persuadieron a muchos de volver a sus lugares de origen. Esto sumado a la falta de servicios, principalmente de sistema de agua potable, de infraestructuras, inexistencia de tendido eléctrico, etcétera, fueron motivo más que suficiente. Sin embargo, hubo quienes habituados a vivir en condiciones de vida similares mientras trabajaban como peones, soportaron en mayor medida tales incomodidades y apostaron por permanecer hasta lograr un solar y convertirse en patrones de sus propias tierras.

\section{LA HUASTECA POTOSINA COMO ESCENARIO DE LAS LUCHAS POR LA TIERRA}

\subsection{Conformación del movimiento agrario}

A fin de comprender la actualidad de los movimientos agrarios en la Huasteca Potosina, es necesario tener en cuenta la situación conflictiva que se generó a raíz de la acción de las compañías deslindadoras, a quienes se opusieron la mayor parte de actores sociales y que puso de manifiesto una fuerte desigualdad en el acceso a la tierra, constituyendo el detonante para la emergencia de toda una serie de demandas sociales. Demuestra esto la tendencia en la región hacia las luchas agrarias sobre la que existen múltiples 
ejemplos entre los que destaca por encima de todos el movimiento de Juan Santiago cuyo epicentro se localizó en el municipio de Tamazunchale ${ }^{8}$.

Aparte de estos actos de rebelión que condujeron a la celebración de numerosos pleitos judiciales, existieron formas de resistencia más sutiles, menos evidentes, más escurridizas para las autoridades. Una de las más estudiadas han sido los condueñazgos. Escobar (2002) reconoce la importancia que adquirieron en el proceso de despojo de las propiedades comunales, convirtiéndose en un recurso esencial para los pueblos indígenas a través de los que conservar sus territorios comunales, o incluso ampliarlos.

Otra estrategia desarrollada por las poblaciones locales fue la repartición de propiedades comunales entre sus miembros, convirtiéndose cada uno de ellos en propietarios privados o convirtiendo en titulares de la tierra a una persona de confianza (Fajardo, 2006).

Pese a estos episodios, no existe una organización consolidada en el marco de las luchas agrarias en la Huasteca. El motivo de ello bien podría ser explicado a partir del hecho de que durante el periodo revolucionario fueron los mestizos quienes lideraron estos procesos. Sus objetivos diferían de los planteados por otros actores sociales lo cual queda reflejado en las demandas actuales que giran en torno a la pretensión de convertirse en parte activa del proceso de producción agraria, fundamentalmente desde que gozan del estatus de propietarios privados y dueños de los medios de producción.

A esto hay que sumar además el hecho de que Gonzalo N. Santos, uno de los políticos más destacados de la Huasteca de mediados de siglo XX obstaculizase los movimientos agraristas. Santos defendió los intereses del sector ganadero ante las amenazas de los campesinos solicitantes de tierras y la presión del gobierno por ejecutar el proyecto Pujal-Coy y con ello las expropiaciones de tierras (Hernández, 2012) ${ }^{9}$.

Pero paulatinamente se fueron forjando movimientos agrarios de relativa significancia. Entre ellos destaca el Campamento Tierra y Libertad, conformado por en torno a 100 grupos de solicitantes. A raíz de la emergencia de este movimiento comenzó el proceso de reparto de tierras de mayor envergadura, en términos cuantitativos, que ha experimentado la región en su historia. Este movimiento fue propiciado por las presiones que veían ejerciendo los ejidos Las Crucitas y Los Otates ante el gobierno del estado desde algunas décadas atrás. Ante la negativa constante de dotación de tierras se decidió invadir un latifundio que ocupaba hasta 7.000 hectáreas, el Rancho Don Tomás, a fin de reclamar la atención de las autoridades. Estos hechos ayudaron a dar a conocer las intenciones del movimiento, incrementando su alcance y difusión entre el sector campesino e indígena de la Huasteca, los cuales se fueron articulando en torno a dicho campamento (Hernández, 2012).

Los años setenta marcaron una época de bonanza económica en el país que impulsó la puesta en marcha de políticas desarrollistas. El capital fluía a un ritmo como nunca antes lo había hecho. El Banco Interamericano de Desarrollo (BID), junto con inversiones privadas, inyectaba capitales pero no sin condiciones.

Al mismo tiempo la situación en el campo se volvía, sin embargo, insostenible para muchos campesinos debido a la desigualdad manifiesta, lo cual llevó a diversos grupos a comenzar a articularse para defender o reivindicar la tierra. Surgieron entonces movimientos, de los cuales hemos perdido el rastro debido a su trayectoria efímera. Es en esta época cuando se produce una explosión de organizaciones rurales a partir de la conformación de uniones de ejidos y grupos de solicitantes de tierras. Los que se extinguieron lo hicieron debido a la concesión por parte de los gobiernos de turno de las demandas solicitadas, básicamente predios agrarios.

El surgimiento de estas organizaciones rurales coincide en el tiempo, no por casualidad, con el arranque del proyecto de riego Pujal-Coy. Entre las más populares y de mayor actividad a nivel sociopolítico cabe señalar, y para la zona que interesa a este trabajo, la Unión de Ejidos Productores Potosinos ${ }^{10}$ y la

8 Carregha (2002) ha contabilizado hasta 14 conflictos armados en el Estado de San Luis Potosí para la primera década del porfiriato (1876-1885), estando ubicados en su mayor parte en la región de la Huasteca.

9 Este personaje acabó finalmente derrotado ante el gobierno estatal, dejó de agradar a los ganaderos, quienes cambiaron su actitud para con él. Sumado a la emergencia de las demandas campesinas junto con las presiones por la realización del proyecto del distrito de riego, sepultaron su carrera política (Hernández, 2012).

10 La unión fue sometida a diversas críticas, entre ellas y tal como ponen de manifiesto Ávila y Cervantes (1986), a una mala administración y malversación de fondos, hasta el momento que llegó a integrarse en la Confederación Nacional Campesina (CNC) (cit. En Baca del Moral, 1996). Para el año 1990 ésta impulsó la creación de algunas organizaciones rurales, tales como la Unión de Ejidos Eusebio García Ávalos en Ponciano Arriaga, la Unión de Ejidos 28 de Marzo en Aurelio Manrique, la Unión de Ejidos Carlos Salinas de Gortari en Santa Martha, Nuevo Aquismón y La Ceiba, etcétera, que constituirían junto con otras organizaciones la Coordinadora Regional de Uniones de Ejidos Solicitantes de Tierra y Poblados de la Huasteca Potosina la cual reunió además de a las ya mencionadas, a grupos 
Central Independiente de Obreros Agrícolas y Campesinos (CIOAC) creada en los municipios de Ébano y Tamuín.

Apenas una década más tarde se impulsaron en el país las políticas de ajuste estructural buscando la modernización del campo por medio de mejoras e inversión en tecnología, concesión de créditos a pequeños productores rurales a través de BANRURAL y una modificación significativa de la legislación agraria que desestructuró el tejido social de los ejidos. Los préstamos se otorgaron con bastante facilidad a ejidos que fungían como sujetos de crédito. Las condiciones del todo flexibles requeridas a la hora de concederlos derivaron en muchos casos en una falta de responsabilidad asumida por individuos que acabaron endeudándose.

Dado que la gran mayoría de los ejidatarios del sector social habían contraído deudas y se venían incapacitados para hacerles frente, se adoptó una solución inmediata. Hacia finales de la década de los ochenta se aprobó la condonación de éstas, lo que no ocurriría sin un acuerdo previo. A los productores se les ofreció la posibilidad de invertir el monto que deberían haber pagado en realizar mejoras en el seno de las comunidades. Sucedió que aquellos que reconocieron la deuda cayeron en una cartera vencida. Esto les ataba a aceptar unas condiciones preestablecidas en caso de solicitar un nuevo crédito. Para convertirse en sujetos de crédito debían ofrecer garantías al banco en cuestión y surgía el problema de que el ejido carecía de documentos que certificasen la titularidad de la tierra (lo que se poseía eran certificados de derechos agrarios), lo que le permitía al banco establecer sus requisitos que obligaban a los solicitantes a comprometerse por escrito a ceder al embargo o incautación de los bienes ejidales en caso del no cumplimiento del acuerdo. Esta situación condujo a que a principios de los noventa se extinguiesen los créditos. Es entonces que al agotarse los recursos, el ejido se vuelve improductivo.

\subsection{Características, estrategias de acción y tipología de conflictos}

El movimiento de lucha por la tierra en la Huasteca responde a unas particularidades que en términos generales no se comparten con otros movimientos del panorama nacional. Si tuviéramos que escoger entre una de ellas ésta sería sin lugar a duda la espontaneidad o la improvisación, condición que responde más al acontecimiento, a respuestas inmediatas locales, lo que ayuda a entender la falta de cohesión interna del propio movimiento. Este quehacer que, sin embargo, no tiene que ver con acciones colectivas inconscientes, responde más a operaciones ejecutadas de manera dispersa y discontinua que se hacen visibles en situaciones decisivas para el movimiento y que al mismo tiempo dificultan su control por parte de los poderes estatales. Gran parte de ellas se desarrollan en la cotidianeidad y el éxito depende en buena medida de la capacidad organizativa y de respuesta adoptada al interior de las organizaciones. En la misma línea de análisis, si bien referido a las poblaciones teenek, señala Baca del Moral (2006) aspectos interesantes de estos movimientos: "ni agresivos ni espectaculares" sino "movimientos permanentes de resistencia", los cuales no crean "grandes estructuras organizativas, y mucho menos las formalizan, prefieren manejar una red de relaciones informales pero perseverantes" (p. 168). Tal planteamiento se hace extensible al conjunto de organizaciones sociales rurales de la Huasteca Potosina.

Después que el Campamento Tierra y Libertad quedase desarticulado, surgieron otros movimientos. El testimonio de uno de los líderes sociales que participó activamente en el proceso de la lucha por la tierra en la región, nos comparte a través de sus palabras los intereses a los que respondían tales organizaciones: "se crearon otros movimientos, el propio mío, yo era muy afín a la CNC (Confederación Nacional Campesina) pero vi que mi organización no se movía, era muy institucional. El mío se llamaba "Movimiento de Campesinos y Colonos", le puse así porque traíamos gente del sector social, gente del campo y gente de las colonias". Otro líder social expresa que hasta el año 1994, cuando se atendió la demanda de 30.000 hectáreas, "no había la cultura de sentarse en una mesa y de aglutinar a todos en un solo movimiento". Pero para entonces, las diferentes organizaciones -MHD (Movimiento Huasteco Democrático), CNC, CCI (Central Campesina Independiente), CODUC (Coalición Organizaciones Democráticas Urbanas y Campesinas), CIOAC (Central Independiente de Obreros Agrícolas y Campesinos), CCC (Central Campesina Cardenista) - se articularon en un único movimiento, con la finalidad de trabajar de manera

de solicitantes de tierras y a los centro de población ejidal (Baca del Moral, 1996). Apenas dos y tres años más tarde se crearon la Asociación Rural de Interés Colectivo (ARIC) y la Alianza de Productores Campesinos de la Huasteca Potosina, respectivamente (ibíd.).

Uno de los principales problemas que señala este autor referido a ambas es la ineficiente estructura organizativa sobre la que nacen y la nula conexión con los campesinos, al ser creadas desde arriba, por lo que aquejan una fuerte verticalidad (ibíd.). 
conjunta, al cual denominaron "Demanda de atención agraria por las 30.000 hectáreas". Estos relatos hablan de una lógica de acción desideologizada que toma forma en el seno de las organizaciones y evidencian hasta qué punto estas acciones no se ajustan a una hoja de ruta diseñada previamente a partir de unos objetivos determinados, sino en el día a día. Sin embargo y pese al intento de articulación del movimiento, no se logró consolidar.

La conformación de tal elenco de organizaciones permitió que se sentaran en una mesa de diálogo la Comisión Nacional de Agua, la Secretaría de Patrimonio Inmobiliario del Gobierno Federal, el Gobierno del Estado, la Secretaría de la Reforma Agraria y la Procuraduría Agraria. Y a través de un proceso de negociación se logró alcanzar un acuerdo para atender la demanda agraria de la superficie mencionada.

Ante la pregunta de porqué no confluyeron antes las organizaciones rurales, la respuesta más frecuente apunta al cacicazgo reinante para aquel entonces en el seno mismo de las organizaciones, sumado a ciertos recelos y reticencias por parte de las dirigencias nacionales, enfrentadas de algún modo por asumir el liderazgo o atender a intereses más particulares en detrimento del bien del común del conjunto de organizaciones, cooptación de líderes o confabulaciones con funcionarios de dependencias del Estado ${ }^{11}$.

La institucionalización de estos movimientos ha diluido la energía social y ha absorbido la capacidad organizativa de sus estructuras internas lo cual se podría deber a la ausencia de mecanismos de control que impiden la desconexión entre los representados y el cuerpo directivo encargado en la toma de decisiones.

Otra de las particularidades tiene que ver con la lógica opositora que enfrenta a diferentes actores sociales e institucionales. Así podemos establecer una tipología de los conflictos en la Huasteca Potosina:

En primer lugar encontramos los enfrentamientos entre pequeños productores y el gobierno de la república y gobiernos estatales, los más frecuentes. Los reclamos más habituales han sido la petición de tierras ejidales e infraestructura. Un ejemplo de ello es lo ocurrido en el centro de población ejidal Ponciano Arriaga, en donde las familias se asentaron sin apenas ningún servicio y tras casi 40 años la situación ha mejorado más bien poco ${ }^{12}$. Muchos campesinos que habían estado durante años trabajando como peones en los ranchos de propietarios privados, tras la adquisición de tierras ascendieron en la escala social, convirtiéndose en patrones.

En segundo lugar cabe señalar los conflictos entre grandes propietarios e instituciones nacionales, surgidos fundamentalmente durante el proceso de expropiación agraria en la década de los setenta. Si bien no tuvieron gran trascendencia debido a que se indemnizó a los propietarios para frenar las protestas, se hizo necesaria la búsqueda de soluciones, no siempre consensuadas debido a la fuerte oposición presentada por los propietarios privados quienes obstaculizaban la conciliación al ver amenazados sus intereses.

En cuanto a los conflictos que involucran a la población indígena, a día de hoy y para los municipios de Ébano y Tamuín, no sobresale ningún movimiento de carácter étnico que de manera autónoma plante resistencia ante los despojos agrarios. Sí se ha producido, por el contrario, una fusión de demandas entre dicho grupo social y la población mestiza ${ }^{13}$.

\subsection{Actualidad de la cuestión agraria y efectos del nuevo marco jurídico}

A día de hoy las demandas de los movimientos por la tierra en la Huasteca Potosina se encaminan a obtener mayor presencia en el mercado para incrementar la productividad, lo cual consideran sólo se podría conseguir con innovación e inversión, así como a través de mejoras tecnológicas, emulando lo que ya ha ocurrido en otras zonas del país.

Desde finales de los ochenta del siglo XX, época que coincidió con el arranque de la segunda fase del distrito de riego de Pujal-Coy, se han dado otros fenómenos no menos importantes que demuestran la continuidad de la tendencia capitalizadora: la dinámica organizacional a nivel ejidal ha sufrido un fuerte

11 Se conocen casos de concesión de ejidos que fueron vendidos nada más ser entregados y casos en los que se utilizó a personas para solicitar la tierra en sus nombres.

12 La diferencia a nivel de infraestructuras entre el poblado de Pujal y de Ponciano Arriaga es que el primero fue creado al interior del distrito de riego en la primera fase, mientras que el segundo fue diseñado para la segunda fase, la cual quedó incompleta. El NCPE Pujal se fundó en 1977, cuando fueron dotados los primeros ejidos por mandato gubernamental de Guillermo Fonseca Álvarez, presidente del estado de San Luis para aquel entonces, en unas tierras en donde la mayor parte de la superficie lo ocupaban ranchos ganaderos.

13 No ocurre lo mismo en la región sur de la Huasteca, en donde existe una fuerte presencia de conflictos étnicos y son, por lo tanto, los grupos indígenas quienes mantienen una lucha más sistemática por la tierra y por los recursos naturales. 
revés quedando visiblemente afectada, sino desintegrada, no se ha evitado el acaparamiento de tierras en manos de grandes propietarios privados, por ende no se ha puesto freno al neolatifundismo, ni fomentado la producción agrícola de manera eficiente, no se ha dado un correcto uso a los recursos de la tierra ni a las infraestructuras hidráulicas incorporadas en el distrito de riego, ni se han incrementado los rendimientos de los cultivos agrícolas. Todo lo cual explica el escepticismo con el que las poblaciones locales acogen las políticas de desarrollo rural implementadas en los municipios de Ébano y Tamuín.

Los ejidatarios de la región huasteca son conscientes de los esfuerzos que deben realizar si no quieren quedarse descolgados del proceso de modernización del mundo rural lo cual genera actualmente las mayores preocupaciones entre los productores locales. Tratan de no quedarse al margen, poder competir frente a otros productores y otras regiones, aun siendo plenamente conscientes de las limitaciones que arrastran. Facilitaría mucho el hecho de pertenecer a una organización campesina fuerte y consolidada, facilitaría los contactos con instituciones, sería menos complicado ser tenidos en cuenta, coordinar acciones conjuntas, dar confianza a los miembros que las conforman, diseñar un plan de acción, etcétera.

Debido al despliegue por parte de los pequeños productores de una línea de acción improvisada, sin haber definido estrategias concretas, los episodios de luchas en el ámbito rural presentan un fuerte carácter local en la Huasteca Potosina. Si en un principio los reclamos se centraban en obtener más tierras para incrementar el número de ejidatarios, poco a poco las reivindicaciones estuvieron puestas en la mejora de infraestructuras y servicios básicos. Mientras que actualmente lo que se pretende es apropiarse del proceso de producción y comercialización agrícola. Este tipo de acciones está asociada a movimientos de baja intensidad ${ }^{14}$.

Los mismos productores que hace cuatro décadas se lamentaban por la falta de tierras, en el momento actual y tras haber experimentado un radical proceso de transformación de su estatus socioeconómico. Al dejar atrás su condición de peones para pasar a convertirse en patrones, plantean sus demandas en otros términos. Han llegado incluso a hacer un llamado de atención a las instancias gubernamentales del estado y de la república con la finalidad de que éstas establezcan convenios con universidades para diseñar programas de estudio y análisis de suelos en la zona de Pujal-Coy, sabiendo que ya se ha realizado con éxito en otras partes del territorio nacional (Nayarit, Guanajuato o Michoacán). Y, a través de ellos, poder conocer las características edafológicas y consecuentemente el tipo de cultivo más adecuado, así como tipos de semillas, cantidad de fertilizantes, etcétera.

Uno de los líderes sociales del NCPE de Pujal se lamenta de las escasas iniciativas que se adoptan en la región, comparándolas con otras que sí han tenido lugar en diferentes lugares de la república. Pone de manifiesto así la mentalidad emprendedora que caracteriza las nuevas luchas no tanto por la tierra, sino por la gestión del proceso de producción así como por la apropiación de las formas de producción dependientes del mercado ${ }^{15}$. Aquellos que han vivido de manera más directa la transformación de su estatus socioeconómico, sacando partido de la modificación del artículo 27 constitucional y favorecidos por la nueva coyuntura legal, han desentendido la organización colectiva representada en el ejido, ante quien ya no sólo no deben rendir cuentas sino que tienen la posibilidad de constituir microempresas de carácter familiar.

Las oportunidades para competir en el mercado regional se ven, en consecuencia, mermadas. De ahí que una de las medidas que los pequeños productores están comenzando a adoptar sea la de asociarse unos con otros en pequeñas empresas. Sin embargo, reclaman subsidios del Estado para que éste apoye el proceso de producción. Tenemos entonces que uno de los efectos de la reforma del artículo 27 de la Constitución mexicana ha sido favorecer las asociaciones privadas de capital, en detrimento de la continuidad de la propiedad ejidal.

Uno de los aspectos a destacar entonces en cuanto a la modificación de dicho artículo es que abre el mercado de tierras al capital privado internacional. Esta modificación se realizó siguiendo las recomendaciones del Banco Mundial y a petición del gobierno norteamericano para la firma posterior del Tratado de

14 Preocupa por ejemplo la caída de precios de los granos, bien sea a nivel nacional como internacional, o la subida de precios de combustibles, de semillas, de productos para el campo, tales como pesticidas, herbicidas o plaguicidas.

15 Relata Baca del Moral (1996) un caso que se produjo en 1991 cuando un grupo de campesinos propuso a varias instituciones -SARH SEDESOL, Gobierno Estatal y BANRURAL- que financiasen un programa de ganado de doble propósito, es decir, de producción de leche y carne, para lo que se demandaban vientres y sementales, sin embargo, no se logró cerrar el acuerdo y hubo que esperar al año siguiente para que impulsado por el candidato a diputado federal de los municipios de Ciudad Valles, Tamuín, Ébano, San Vicente y Tanlajás se destinaran hasta 2 millones de pesos de cara a poner en marcha dicho proyecto. 
Libre Comercio de América del Norte (TLCAN), dos años más tarde, tras el acuerdo alcanzado entre México, Estados Unidos y Canadá y que entró en vigor el 1 de enero de 1994, coincidiendo no por casualidad con el levantamiento del Ejército Zapatista de Liberación Nacional (EZLN). Su aplicación se acompañó con el anuncio de contrarrestar la bajo productividad de la tierra y favorecer el desarrollo rural del agro mexicano, así como su modernización. Y sin embargo, lo que ocurrió fue la descomposición social del ejido, efecto de esta tendencia capitalizadora resultante. Asimismo la dotación de tierras llegaba a su fin.

Sin embargo y tal y como lo señala Medina (2006), los intentos por implantar medidas de corte neoliberal en el campo mexicano que transformasen la estructura agraria, afectando particularmente a formas de propiedad colectivo-ejidales se venían gestando desde el arranque de la década de los ochenta.

Todo esto aparece relacionado con las inquietudes que sufren los pequeños productores en cuanto a las iniciativas para incrementar la rentabilidad de la producción, que les lleva incluso a plantear lanzar propuestas a los industriales de la región con la intención de construir una planta industrializadora de aceite de soja en Ébano. Lo que se pretende con esto es aplacar la baja rentabilidad de dicho producto, el cual una vez cosechado es exportado a otras zonas del país. Veamos el ejemplo de la soja: hasta hace dos años se obtenían 8.300 pesos por tonelada en el mercado, momento en el que la cifra descendió hasta los 5.300. De cara a enfrentar este tipo de situaciones los pequeños productores de la Huasteca Potosina requieren, por lo tanto, más ayudas gubernamentales destinadas al campo con las que aumentar la productividad y competir con otros mercados. Sin embargo, se lamenta este sector social, las ayudas del Estado son insuficientes y tardan demasiado en llegar.

En el poblado de Pujal se está produciendo una situación particular al haberse enfrascado un grupo de productores en un nuevo proyecto. Han conformado para ello una comisión integrada por personas procedentes de varios centros de población de los municipios de Ébano y Tamuín, la cual a día de hoy se encuentra a la espera de obtener la personalidad jurídica para de este modo poder encauzar proyectos de alto impacto, convirtiéndose entonces en sujetos de crédito y teniendo representación en el sector social. El empoderamiento a nivel político, favorecido por la representación en los ayuntamientos a través de un consejero en la Secretaría de Desarrollo Agropecuario y de Desarrollo Social, permitiría, por un lado, disputar desde instancias municipales asuntos vinculados directamente con el sector de los pequeños productores a fin de conseguir mayores inversiones en el campo conducentes a incentivar el diseño de nuevas políticas de desarrollo rural para la Huasteca. En segundo lugar esto derivaría como consecuencia en una mayor autonomía en términos económico-productivos, permitiendo evitar los tratos informales y las transacciones de compra-venta frente a intermediarios o coyotes, como así se denominan coloquialmente en la región, para de esta manera obtener precios más acordes con la mercancía comercializada.

Todo lo cual implica que a fin de estimular y fomentar la inversión y la innovación en el campo, los pequeños productores requieren entonces de ayudas del Estado en forma de subsidios, que les arrope y les dé seguridad para emprender tales empresas, algo esencial para poder hacer frente a la producción cíclica del campo, tal y como señala Warman (2001). Lo que significa que estos productores quedan sujetos al financiamiento, visto como la opción más factible para el desarrollo de sus proyectos. No obstante, aclara este autor, en lo referente a los subsidios públicos, y en particular aquellos destinados a la agricultura de irrigación, "el 10\% de los productores rurales captan la mayor proporción" (ibíd. 189).

No obstante y al mismo tiempo quedan bajo riesgo de endeudamiento y a merced de los procesos de acumulación del capital en caso de que la banca, sin ningún tipo de control por parte de la administración del Estado, continúe operando bajo la lógica del máximo beneficio. Estos se encuentran, por lo tanto, atrapados en la encrucijada de defender sus intereses de clase o dejarse arrastrar por la espiral capitalista que en último término puede despojarles del frágil control del proceso productivo que a día de hoy mantienen no sin muchas inseguridades. En caso de que se diese el segundo escenario fácilmente desembocaría en una nueva proletarización agraria de este sector rural, con las consecuencias que de ello se derivan (migración, pérdida de poder adquisitivo, riesgos de vulnerabilidad social, incremento de niveles de pobreza rural, descomposición del tejido social en el campo, etcétera). Sea como sea la estructura agraria no busca en realidad ser transformada y, sin embargo, los conflictos sociales se encuentran en estado latente por las contradicciones que definen al mundo rural en la región.

Es por esto que las medidas más viables que vislumbran de cara a paliar la vulnerabilidad que envuelve a su sector es la asociación de productores rurales. Sería éste el modo para hacer frente a las intermediaciones informales y a la escasa representación y participación en las esferas institucionales al lograr la independencia que a día de hoy aún les ata a los grupos de poder. 


\section{A MODO DE REFLEXIÓN}

El mundo rural de la Huasteca Potosina se ha visto históricamente atravesado por una conflictividad latente que comenzó a agudizarse a raíz de la implementación de las leyes liberales las cuales desataron el proceso de desamortización de bienes comunales. De la mano de dicho proceso se produjo un incremento de la superficie ocupada por las grandes haciendas, las que se consolidaron como principal unidad económico-productiva en la región. Requirieron mano de obra campesina que fue absorbida para trabajar en las grandes propiedades privadas, convirtiéndose en peones. Alrededor de un siglo más tarde y como parte de las políticas de desarrollo rural implementadas a lo largo y ancho del territorio de la república, se vislumbró la posibilidad de poner en marcha, y aprovechando las características geomorfológicas del entorno, proyectos hidráulicos que reactivaran la producción agrícola. Fruto de ellos fue la reestructuración profunda de la tenencia de la tierra en la Huasteca, debido fundamentalmente a que uno de los objetivos prioritarios del programa de riego Pujal-Coy era el de incrementar la superficie dedicada a cultivos agrícolas. Esto fue lo que sedujo a un importante número de personas para conformar los grupos de solicitantes de tierras, quienes lograron convertirse en ejidatarios gracias al proceso de dotación agraria. Buena parte de ellos habían trabajado como peones en haciendas de la región. Otros muchos provenían de diversas partes de la república y de manera súbita se convirtieron en propietarios ejidales.

Paulatinamente y tras superar un proceso de aprendizaje colectivo en todos los niveles, son cada vez más los productores locales que apuestan por apropiarse del proceso de producción agraria y ser parte activa del mismo. Si para la década de los setenta del siglo pasado este colectivo de productores rurales pugnaba por la apropiación de la tierra, en la actualidad y una vez satisfechas sus demandas iniciales, de lo que se trata es de consolidar, incluso de aumentar, un estatus socioeconómico logrado en buena medida a raíz de la modificación del artículo 27. A raíz de éste gozan, en calidad de propietarios privados, de una mayor autonomía y margen de acción en el marco de las relaciones sociales de producción. Los cambios introducidos en el artículo 27 supusieron una estrategia del Estado que actuó como elemento desarticulador de las relaciones sociales de carácter comunal al interior de los ejidos. Esta maniobra legal ha sido trascendental por dos razones básicas. En primer lugar por debilitar internamente los dispositivos de cohesión interna, los lazos de reciprocidad y los vínculos afectivos de los núcleos ejidales. En segundo lugar y estrechamente vinculado con lo anterior, por haber propiciado una transformación sustancial del carácter de las demandas. Ambos fenómenos se han derivado del proceso de separación de la esfera política y la esfera económica. Sumado a ello, la institucionalización de estos grupos, propiciado por la regulación estatal, comprende aceptar y cumplir ciertas normas establecidas a través de mecanismos de poder que otorgan la personería jurídica.

Del mismo modo que ocurre de manera frecuente en el seno de los movimientos sociales, sean del signo que sean, la inserción de estos en los canales de acción diseñados por el modelo neoliberal para ceder un espacio de acción restringido a aquellos, limita su potencial transformador y contribuye de manera indirecta a legitimar las lógicas estatales que responden a dicho modelo, así como a consolidar el poder hegemónico de éste. De esta manera se corre el riesgo de subordinar los objetivos iniciales de las luchas que marcan el rumbo de estos movimientos. En el marco de las luchas sociales los acuerdos y las negociaciones forman parte de la relación entre el Estado y los movimientos en cuestión. Y sin embargo, esas estrategias improvisadas a las que responden las acciones de los movimientos agrarios en la Huasteca, la ausencia de programas de acción previamente definidos, no son indicativos de una falta de reflexión en el seno del movimiento en sí. Por el contrario, otorgan una naturaleza creativa y de mayor flexibilidad al mismo, desde la que plantear soluciones en el marco de las relaciones establecidas para con el Estado y las instituciones dependientes de éste.

Los movimientos agrarios de la Huasteca brindaron, en su origen, la posibilidad de operar cambios en el escenario rural de la región a través de prácticas espaciales concretas con las que se pretendía hacer frente a la propia espacialidad del Estado instituida por los poderes gubernamentales. La ruptura que se ha vivido en el seno de tales movimientos abre muchas dudas acerca de las estrategias transformadoras de estos. Desde el momento en el que los productores rurales se han convertido en propietarios privados resulta más que discutible la transformación de la representación del espacio, construido para beneficiar a quienes forman parte activa del proceso productivo y de gestión de recursos. En su papel de propietarios a lo que aspiran es a promover la inserción en el mercado nacional. En tanto que las iniciativas de las organizaciones rurales no muestren una total independencia frente a la institucionalidad estatal será 
complicado romper con la subordinación histórica a la que los sectores campesinos se han visto históricamente sujetos y que a día de hoy se agudiza aún más bajo la dominación de la lógica del capital.

En este sentido es interesante llamar la atención sobre el proceso de transformación que ha experimentado el grupo de los propietarios privados, sobre el ascenso a nivel socioeconómico que supuso la conversión progresiva de peones a patrones, lo cual justifica por lo tanto, el objetivo principal que se ha marcado explorar la presente investigación. Tal transformación ha ido de la mano de una progresiva modificación de las prácticas espaciales en términos lefebvrianos que desafían la territorialidad estatal y que a su vez han contribuido a generar una multiplicidad de espacios los cuales se superponen, a la vez que se enfrentan en un esquema de dominación/resistencia que espacializa las relaciones de poder entre diversos actores sociales, bien sean las organizaciones del campo, la sociedad civil en su conjunto, grandes empresas del sector agrícola y ganadero o incluso el propio Estado.

Las disputas por la apropiación de un territorio determinado, su control y explotación brindaron una oportunidad a las poblaciones locales de la Huasteca para plantear nuevas formas de organización territorial enfrentadas a las lógicas de ordenación del espacio de los grupos de poder. Sin embargo, inmersos en procesos de acumulación de capital que les catapultó a un nivel superior en la jerarquía social. Absorbidos por flujos económicos de producción regional, los intereses locales viraron hacia otros rumbos y las nuevas territorialidades encarnadas en los conflictos surgidos en los primeros años de las luchas de los movimientos agrarios de la Huasteca, no alcanzaron el carácter transformador de la realidad social, que algunos preconizaron por aquel periodo. Es decir, las luchas agrarias no han resuelto el problema de la tierra en esta región.

Recapitulando todo lo comentado hasta el momento nos asaltan algunas cuestiones que sin la intención de que sean respondidas, quedan planteadas a modo de reflexión: ¿se ha logrado frenar la desigualdad que ha caracterizado al agro en la Huasteca Potosina?, ¿se ha conseguido redistribuir la tierra en base a una mayor justicia social? Y es que pese a las restricciones que dictamina la legislación agraria mexicana, continúan existiendo grandes propietarios que acaparan grades extensiones de tierra, apuntando a que aún no se ha dado fin al latifundio en la región.

\section{REFERENCIAS}

Baca del Moral, J. (1993). Análisis de los ámbitos agrícolas en la zona del Pujal-Coy. En J. Ruvalcaba y G. Alcalá (Coords.), Huasteca II. Prácticas agrícolas y medicina tradicional. Arte y sociedad (pp. 101-107). México D. F: CIESAS.

Baca del Moral, J. (1996). Tendencias de la agricultura en la Huasteca Potosina. Revista de Geografía Agrícola, 24-25, 85-97. Recuperado de http://chapingo.net/articulo24-25/tendenciasdelaagricultura.pdf

Baca del Moral, J. (Coord.) (2006). El desarrollo de la encrucijada: ¿sustentabilidad para quién? Chapingo: Universidad Autónoma de Chapingo.

Barthas, B. (1993). Sistemas de producción y conflictos agrarios en la Huasteca Potosina (1870-1910). Revista Cuadrante, (11-12), 30-42.

Bartra, A. y Otero, G. (2008). Movimientos indígenas campesinos en México: la lucha por la tierra, la autonomía y la democracia. En S. Moyo y P. Yeros (Coords.), Recuperando la tierra. El resurgimiento de movimientos rurales en África, Asia y América Latina. Sam Moyo y Paris Yeros (pp. 401-428). Recuperado de http://bibliotecavirtual.clacso.org.ar/ar/libros/sursur/moyo/18BarOt.pdf

Carregha, L. (2002). En torno a los levantamientos armados en la Huasteca Potosina al inicio del porfiriato. En A. Escobar y L. Carregha (Coords.), El siglo XIX en las Huastecas (pp. 167-184). México D.F., San Luis Potosí: CIESAS, COLSAN.

Escobar, A. (2002). ¿Qué sucedió con la tierra en las Huastecas decimonónicas?. En A. Escobar y L. Carregha (Coords.), El siglo XIX en las Huastecas (pp.137-165). México D.F., San Luis Potosí: CIESAS, COLSAN.

Escobar, A. (2009). Estudio introductorio. Haciendas, pueblos y recursos naturales en San Luis Potosí (1856-1916). En A. Escobar y A. M. Gutiérrez (Coords.), Entretejiendo el mundo rural en el Oriente de San Luis Potosí, siglos XIX y XX (pp. 19-98). México D.F., San Luis Potosí: CIESAS, COLSAN. 
Fajardo, G. (2006). El impacto de las leyes liberales en la Huasteca Potosina: 1856-1910. Tesis para Lic. en Historia. México D. F: Universidad de Iztapalapa.

Fajardo, G. (2009). La privatización de la tierra y problemas agrarios en la Huasteca Potosina, 1870-1920. En A. Escobar y A. M. Gutiérrez (Coords.) Entretejiendo el mundo rural en el Oriente de San Luis Potosí, siglos XIX y XX (pp. 99-135). México D.F, San Luis Potosí: CIESAS, COLSAN.

Gutiérrez, A. M. (2009). El condueñazgo de los Moctezuma. Origen y defensa de la tierra, 1880-1929". En A. Escobar y A. M. Gutiérrez (Coords.) Entretejiendo el mundo rural en el Oriente de San Luis Potosí, siglos XIX y XX (pp. 237-262). México D.F., San Luis Potosí: CIESAS, COLSAN.

Hernández, G. (2012). Las transformaciones agrarias y el impacto del PROCEDE entre los tenek de la Huasteca Potosina. Un análisis multiescalar. Tesis Doctor Geografía. México D. F: UNAM.

Hoffmann, O. y Salmerón, F. (1997). Introducción. Entre representación y apropiación, las formas de ver y hablar del espacio. En O. Hoffman y F. Salmerón (Coord.) Nueve estudios sobre el espacio. Representación y formas de apropiación (pp. 14-29). México D. F: CIESAS.

Lefebvre, H. (1991) [1974]. The production of space. Oxford: Blackwell.

López, M. A. (2008). El Frente Ciudadano Doctor Salvador Nava Martínez. Democracia y cultura política en el sur de la Huasteca Potosina. México D.F., San Luis Potosí: CIESAS, COLSAN y UASLP.

Meade de Angulo, M. (1983). La Huaxteca Potosina en la época colonial. Siglo XVI. México D.F:: Academia Potosina de Ciencias y Artes.

Medina, S. (2006) La Reforma del Artículo 27 Constitucional y el Fin de la Propiedad Social de la Tierra en México. El Colegio Mexiquense, 1-21. Recuperado de http://www.cmq.edu.mx/index.php/docman/ publicaciones/doc-de-investigacia-n/254-di1210407/file

Reyes, H., Aguilar, M., Aguirre, J. R. y Trejo, I. (2006). Cambios en la cubierta vegetal y uso del suelo en el área del proyecto Pujal-Coy, San Luis Potosí, México, 1973-2002. Investigaciones Geográficas, Boletín del Instituto de Geografía, 59, 26-42. Recuperado de http://www.revistas.unam.mx/index.php/ rig/article/view/30019

Warman, A. (2001). El campo mexicano en el siglo XX. México D.F: Fondo de Cultura Económica.

Wolf, E. (1972). Las luchas campesinas del siglo XX. México: Siglo XXI. 